\title{
Pro Matre: arquivo e fontes para a história da maternidade no Rio de Janeiro
}

\author{
Pro Matre: an archive and sources on the history \\ of motherhood in Rio de Janeiro
}

\author{
Maria Renilda Nery \\ Barreto \\ Professora e pesquisadora do \\ Centro de EducaçãoTecnológica \\ Celso Suckow da Fonseca, Rio de \\ Janeiro. \\ Av. Maracanã, 229 \\ 20271-110 - Rio de Janeiro - RJ - \\ Brasil \\ renildabarreto@hotmail.com
}

BARRETO, Maria Renilda Nery. Pro Matre: arquivo e fontes para a história da maternidade no Rio de Janeiro. História, Ciências, SaúdeManguinhos, Rio de Janeiro, v.18, supl.1, dez.2011, p.295-301.

\section{Resumo}

A quase centenária Maternidade Pro Matre, inaugurada em fevereiro de 1919, com a finalidade de prestar assistência a mães e crianças dos grupos sociais menos favorecidos, foi iniciativa do médico filantropo Fernando Magalhães e da feminista Stella de Carvalho Guerra Duval com apoio de senhoras da sociedade carioca. Sua criação inseriu-se em movimento de assistência materno-infantil que a historiografia hoje chama de projeto maternalista, com base na ideia de que mãe e filho são culturalmente indissociáveis. Ao apresentar as fontes existentes no arquivo institucional da Pro Matre, partilhamos possibilidades de pesquisa no campo da assistência materno-infantil no Rio de Janeiro e, por extensão, no Brasil.

Palavras-chave: Pro Matre; assistência materno-infantil; Brasil; Fernando Magalhães (1871-1944); filantropia.

\section{Abstract}

Inaugurated in February 1919 to provide assistance to mothers and children from underprivileged social groups, the nearly century-old Maternidade Pro Matre maternity hospital was an initiative of physician and philanthropist Fernando Magalhães and of feminist Stella de Carvalho Guerra Duval, with the support of society women from Rio de Janeiro. Its creation was part of a motherchild assistance movement that historiography now calls the 'maternalist project,' which was based on the notion of the cultural inseparability of mother and child. The sources available at Pro Matre's institutional archive open up research possibilities in the field of mother-child assistance in Rio de Janeiro and, by extension, Brazil.

Keywords: Pro Matre; mother-child assistance; history of maternity; Fernando Magalhães (1871-1944); philanthropy. 
Amparar, dirigir, educar a infância, mas principalmente higienizála, torná-la sadia e forte, evitar-lhe a pavorosa mortalidade atual, são o dever formal, inadiável, categórico das gerações presentes.

Plínio Olinto (1940, p.5)

Na virada do século XIX para o XX, alguns segmentos urbanos demonstraram preocupação com os elevados índices de mortalidade infantil, considerados incompatíveis com a almejada construção da nacionalidade. Nesse contexto nacionalista e higienista, os médicos e os puericultores, com o apoio das elites e de setores femininos da sociedade, organizaram entidades de assistência materno-infantil, movimento que visava, entre outros objetivos, à conformação de rede de assistência focada na construção de instituições hospitalares especializadas em obstetrícia e pediatria, e de espaços de educação feminina voltados para o cuidado da infância. Os médicos e a filantropia laica foram os pioneiros na defesa da assistência materno-infantil. Em seguida, o movimento ganhou o apoio das camadas urbanas média e alta.

Os médicos eram os principais defensores de um espaço hospitalar reservado às gestantes e aos cuidados dos recém-nascidos. Essas ideias eram difundidas nas páginas dos periódicos leigos e especializados, nas sessões da Academia Nacional de Medicina e da Câmara Municipal, nos congressos médicos, nas faculdades de medicina, entre outros espaços.

No Rio de Janeiro, durante a década de 1870 o poder público ensaiou criar um órgão municipal - a Maternidade Santa Isabel - que deveria prestar assistência às mulheres pobres e 'necessitadas', assim como dotar a Faculdade de Medicina do Rio de Janeiro de ambiente adequado às aulas da clínica de partos. Contudo, divergências de interesses entre o Poder Executivo central e o Distrito Federal encerraram o projeto de construção de edifício próprio para a Maternidade Santa Isabel, e a cidade do Rio de Janeiro teve que esperar até 1904 para ter a sua maternidade.

Estabelecida em Laranjeiras, ela materializou um anseio antigo dos médicos, em especial dos catedráticos da Escola de Medicina do Rio de Janeiro. O projeto foi apoiado pelo poder público e pela ala feminina da sociedade carioca, a qual fundou, em 26 de novembro de 1903, a Associação Auxiliadora da Maternidade, com sede na própria entidade e tendo por função auxiliar a diretoria médica na manutenção do estabelecimento e na fundação do patrimônio.

A articulação entre esses dois segmentos se fez presente na organização de outra instituição de caráter filantrópico, com objetivo social mais amplo do que o da Maternidade de Laranjeiras. Estamos nos referindo à Associação de Caridade e Auxílio Mútuo, designada Pro Matre, a qual fundou e manteve instituições de cuidados materno-infantis, entre elas uma maternidade. A Maternidade Pro Matre teve tamanha ressonância, que passou a ser confundida com a Associação Pro Matre e até colocá-la na sombra. O acervo documental da quase centenária Maternidade Pro Matre e suas possibilidades de análise historiográfica são o objeto de nossa atenção neste breve artigo.

A Associação Pro Matre foi criada em abril de 1918, com a finalidade de "dispensar proteção à mulher desvalida sem distinção de credos religiosos ou posição social" exercendo 
a mutualidade, fundando maternidades, policlínicas, creches, cantinas, refúgios, oficinas e asilos maternais (Estatutos..., 1918, p.3-4). À medida que o projeto social foi-se concretizando, a Associação Pro Matre estendeu seus benefícios às crianças consideradas 'desvalidas', como apontam os estatutos da instituição.

Esse movimento em defesa da mulher e da criança inscreve-se no contexto de organização da assistência pública e redefinição das ações privadas no Brasil, na virada do século XIX para o XX, especialmente na capital federal: o Rio de Janeiro. Médicos e juristas, a exemplo de Fernando Magalhães (1878-1944) e Ataulfo de Paiva (1867-1955), defenderam a necessidade de "salvar o filho, amparar a mãe; depois formar o cidadão" (Assistência..., 1922). Dessa forma, a assistência maternal englobava cuidados médicos, amparo e recolhimento para a parturiente, bem como a educação dessas mulheres visando à formação física e moral das crianças. A execução desse projeto se daria a partir das maternidades, compreendidas como espaços a serem organizados nos moldes higiênicos e antissépticos, capazes de disseminar medidas preventivas entre as mães, quer no espaço hospitalar, quer na assistência em domicílio. Além disso, o aleitamento também era fator de preocupação do poder público e dos assistencialistas, bem como a fundação das creches para abrigar as crianças durante a jornada de trabalho das mães, especialmente as operárias.

Médicos, juristas e intelectuais que se ocuparam do binômio mãe e filho atribuíram às mães a responsabilidade pela formação física e moral de suas crianças, os futuros cidadãos brasileiros. Se de um lado tal responsabilização encontra-se em sintonia com o ideário maternalista de valorização das mulheres por sua natureza específica para a maternidade, de outro, implica a necessidade da educação feminina com esse fim, sobretudo quanto aos princípios da higiene (Freire, 2008).

Esse foi o período de redefinição das ações da assistência pública e privada, em que membros da sociedade tornam-se parceiros do Estado e empreendem ações afinadas com as demandas oficiais. As entidades filantrópicas criadas no início do século XX se apresentam como outro modelo de serviço social substitutivo das tradicionais práticas de caridade. Diante do crescimento da demanda por serviços de saúde e assistência, e da limitada capacidade do poder público em responder a tais necessidades, observa-se a associação entre medicina e filantropia (Freire e Ferreira, 2011; Sanglard, 2008).

Os programas de assistência médica e proteção social materno-infantil que começaram a se esboçar no início do século XX, em especial nas grandes cidades brasileiras, possuíam objetivos amplos, conforme se pode depreender dos estatutos do Instituto de Proteção e Assistência à Infância (Ipai). Fosse na matriz carioca ou em sua congênere baiana, o Ipai preconizava, entre outras ações, proteção às "crianças pobres, doentes, defeituosas, maltratadas e abandonadas moralmente"; acompanhamento das mulheres grávidas; difusão das noções de higiene infantil entre as famílias de baixa renda; regulamentação do trabalho da mulher na indústria; criação de asilos maternais, de creches e de jardins de infância (Registro..., 20 mar. 1911).

A Associação Pro Matre percorreu uma trajetória muito semelhante à dos Institutos de Proteção e Assistência à Infância, no intuito de realizar o que a historiografia hoje chama de projeto maternalista, com base na ideia de que mãe e filho são culturalmente indissociáveis (Freire, 2009). A primeira ação filantrópica da Associação foi a criação de uma maternidade 
que abriu suas portas em fevereiro de 1919, resultado do trabalho conjunto da feminista Stella de Carvalho Guerra Duval (1879-1971), presidente da Associação Pro Matre; do filantropo, médico e professor de clínica obstétrica da Faculdade de Medicina do Rio de Janeiro Fernando Magalhães; e das Damas da Cruz Verde ${ }^{1}$, grupo de 14 senhoras da sociedade carioca que desempenhou importante papel na viabilização do projeto, através da busca de recursos para construção e aparelhamento da maternidade, bem como em sua administração.

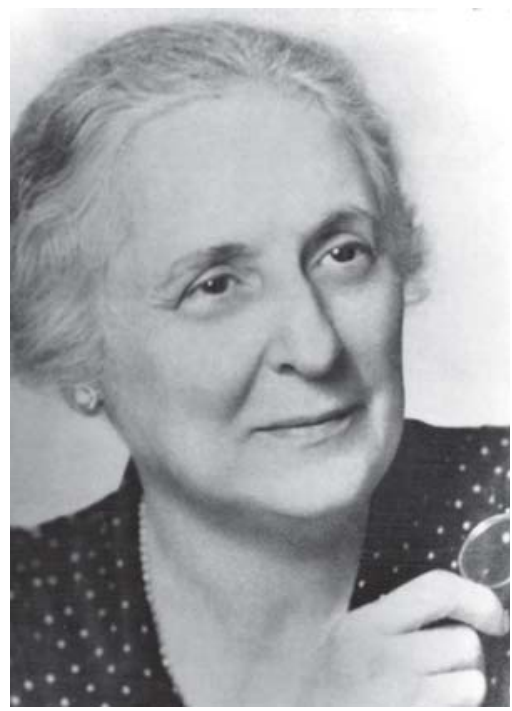

Figura 1: Dona Stella de Carvalho Guerra Durval, fundadora da Pro Matre e sua primeira presidente; s.d. (Acervo Pro Matre)

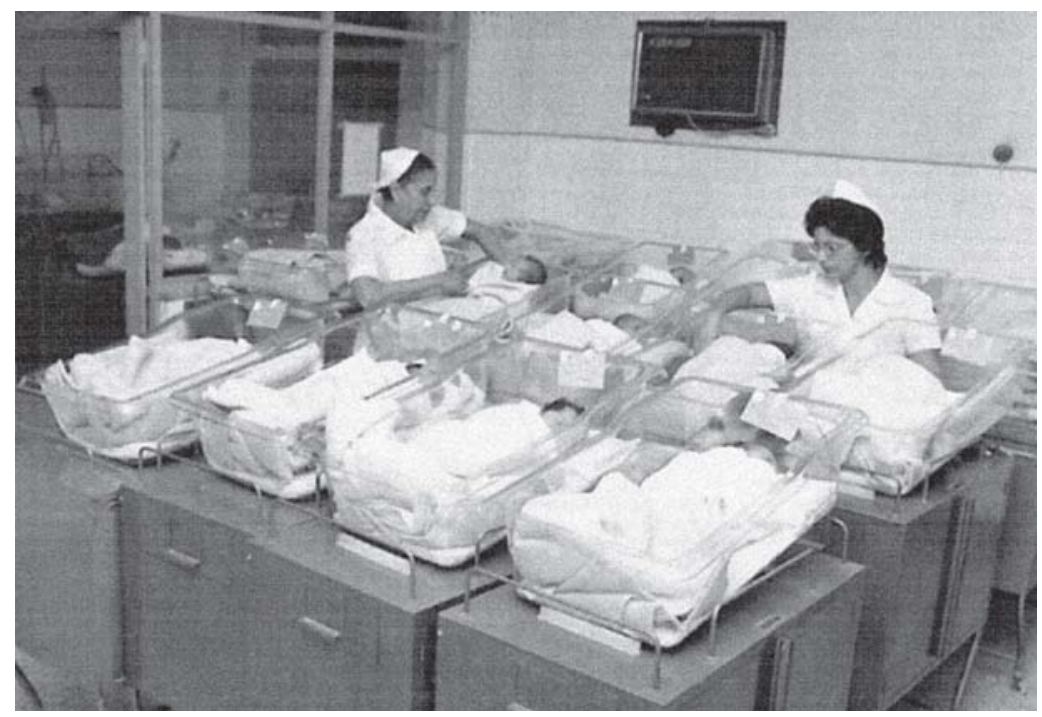

Figura 2: Berçário da Pro Matre, s.d. (Acervo Pro Matre)

A fundação da Maternidade Pro Matre acompanhou os primórdios de um movimento que marca a transição do parto doméstico para o hospitalar. Ana Paula Vosne Martins (2005) afirma que no Brasil essa transição ocorreu a partir dos anos 1930, atingindo diferentemente as mulheres conforme a classe social e a raça.

A historiografia especializada vem produzindo estudos nesse campo nas últimas quatro décadas, principalmente nos EUA e na Europa. Na América Latina ${ }^{2}$ e, em particular, no Brasil ${ }^{3}$, essa é uma temática que vem interessando pesquisadores; com isso, já contamos com publicações significativas, além dos estudos desenvolvidos nos programas de pósgraduação. Ainda que tenhamos pesquisas em andamento e expressivos trabalhos vindo a lume, há que assinalar a lacuna historiográfica sobre a história da assistência maternoinfantil no Brasil.

A documentação da Maternidade Pro Matre está sendo trabalhada no âmbito de dois projetos: "Os Filantropos da Nação: uma história da assistência da Primeira República à Era Vargas", financiado pela Fundação de Amparo à Pesquisa do Estado do Rio de Janeiro (Faperj); e "Ciência e filantropia na construção da assistência no Rio de Janeiro: o caso da Pro Matre (1917-1947)", financiado pelo Centro Federal de Educação Tecnológica Celso Suckow da Fonseca (Cefet-RJ). O primeiro tem como objetivo analisar a transição do modelo de assistência eminentemente filantrópico para a formação de uma rede de 
assistência pública no Brasil da primeira metade do século XX. O segundo projeto tem por finalidade examinar como a Pro Matre se articulou a essa rede de assistência, tomando-a como exemplo de interação entre políticas públicas, aplicação de práticas médicas inovadoras e ações de caráter assistencial-filantrópico. Esse estudo procura perceber a história da maternidade no Brasil a partir do olhar institucional, ou seja, da organização de um hospital especializado para prestar atendimento e cuidados sociais a mulheres e crianças.

O rico acervo da Pro Matre, contudo, abre

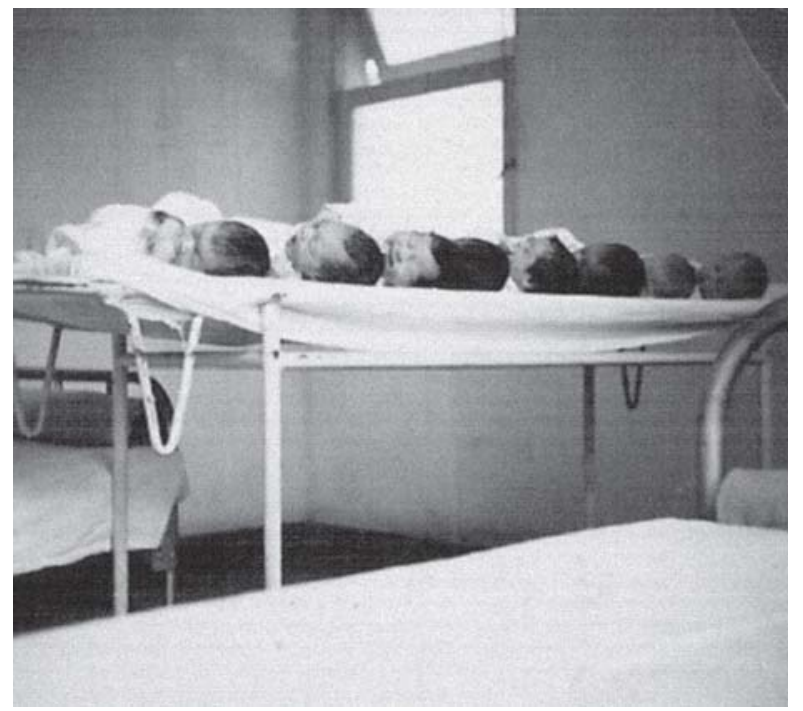

Figura 3: Neonatos na Pro Matre, s.d. (Acervo Pro Matre) outras possibilidades temáticas e metodológicas - mas, afinal, que tesouros guarda o arquivo histórico da Pro Matre?

\section{Visita às fontes}

Conforme o subtítulo sugere, não faremos uma discussão pormenorizada do conjunto de documentos nem pretendemos dar conta de todas as possibilidades de análise que o arquivo da Maternidade Pro Matre oferece ao pesquisador. Ao tornar público o inventário das fontes, mediante descrição geral do acervo da instituição, esperamos despertar a atenção dos pesquisadores para o valioso conjunto documental e enunciar algumas áreas de interesse e de pesquisa, sem, contudo, as esgotar.

Quando a atual presidente da Pro Matre, Vera Lúcia de Souza Coelho Wanderley, acolheu nosso pedido de pesquisa no acervo promatriano, nos deparamos com várias caixas e pastas de documentos. O acervo não possui catalogação nem guia de fontes, e algumas obras demandam higienização e restauro. Ao longo dos quase cem anos de existência da Pro Matre, muitos documentos foram descartados, quase sempre sem passar por triagem e, muitas vezes, sem a anuência da presidência. Foram guardados, entretanto, livros de atas da diretoria e do conselho fiscal; Livro de Ouro; documentos cartoriais; registros das campanhas organizadas com o propósito de angariar doações; cópias de publicações em Diário Oficial; doações e testamentos; cartilhas para orientação das mães; revistas médicas; livros de memória; recortes de jornais; boletins clínicos e administrativos; estatutos; procurações; plantas das sucessivas reformas empreendidas no edifício hospitalar; correspondências; e significativo acervo iconográfico, composto por fotografias. ${ }^{4}$

Por conta dos limites desta seção, nos restringimos a apresentar uma coleção de fontes denominada Boletim da Pro Matre. Trata-se de fonte impressa, encadernada e seriada correspondendo aos meses de cada ano, entre 1937 e 1983 -, editada pela Associação Pro Matre. Sua redação ficou a cargo da diretoria, e a distribuição se fazia por meio de assinaturas anual ou mensal, ou compra avulsa.

A primeira seção do Boletim abordava temas considerados marcantes na rotina anual da instituição. Vamos tomar como exemplo os anos de 1937 e 1938. Nesse período a seção 
noticiou a construção e inauguração do pavilhão Luiz da Rocha Miranda, executado com donativo da família Rocha Miranda durante a campanha de 1933; os preparativos para a Semana das Crianças, em 1937; a expansão do abrigo infantil pela compra de prédio na rua Barão de Itambi; a criação de um quarto particular para senhoras de jornalistas e a instalação de um leito na enfermaria geral para senhoras trabalhadoras de jornal, como homenagem da Pro Matre à imprensa carioca; notícias sobre a campanha financeira em conjunto com o Serviço de Obras Sociais (SOS) e a Cruzada Nacional Contra a Tuberculose. Era sempre anunciada a composição da diretoria, dos conselhos consultivo, deliberativo e técnico, bem como do corpo médico.

As seções seguintes tratavam dos donativos, do balancete institucional e do movimento geral do hospital. A de donativos permite realizar o inventário dos doadores e mantenedores da instituição, e também a análise prosopográfica da filantropia da elite no período, em particular da filantropia feminina.

A documentação da Maternidade Pro Matre nos remete à construção da memória da instituição e à afirmação da sua identidade. Utilizar-se dos arcabouços teóricos e metodológicos da história para examinar essas fontes é poder partilhar com a sociedade a história e a memória da assistência materno-infantil no Rio de Janeiro e, por extensão, no Brasil. As análises dessas fontes certamente nos permitirão conhecer as concepções, os modelos e as transformações na assistência à saúde da população, as políticas de saúde pública implantadas durante a República, os atores sociais envolvidos no quotidiano da Pro Matre, entre inúmeros outros elementos deste grande painel a que chamamos história da assistência materno-infantil.

\section{NOTAS}

${ }^{1}$ A criação dessa e de outras associações femininas em torno da filantropia foi prática recorrente entre as mulheres de elite em cidades como Rio de Janeiro, São Paulo (Mott, 2001, 2005) e Salvador (Freire, Ferreira, 2011).

${ }^{2}$ Com relação à Argentina, deve-se atentar para as publicações de Billorou, 2007; Nari, 2004; Di Liscia, 2002. Sobre o Chile, ver trabalho de Zárate, 2007.

${ }^{3}$ Salientam-se os artigos e livros publicados por Ana Paula Vosne Martins (2005) e Maria Martha de Luna Freire $(2008,2009)$.

${ }^{4}$ Aos pesquisadores interessados em trabalhar com o acervo Pro Matre informamos que é necessário pedir autorização à presidência.

\section{REFERÊNCIAS}

ASSISTÊNCIA...

Assistência pública e privada no Rio de Janeiro (Brasil). Rio de Janeiro: Typografia do Annuario de Brasil. Edição comemorativa do centenário da independência do Brasil. 1922.

BILLOROU, María José.

Madres y médicos en torno a la cuna: ideas y prácticas sobre el cuidado infantil (Buenos Aires, 1930-1945). La Aljaba, Buenos Aires, v.11, p.167-192. 2007.
DI LISCIA, María Silvia.

Hijos sanos y legítimos: sobre matrimonio y asistencia social en Argentina (1935-1948). História, Ciências, Saúde - Manguinhos, Rio de Janeiro, v.9, supl., p.209-232. 2002.

ESTATUTOS...

Estatutos da Associação Pro Matre. Rio de Janeiro: Oficinas Gráficas de A Noite. 1918. 
FREIRE, Maria Martha de Luna.

Mulheres, mães e médicos: discurso maternalista no Brasil. Rio de Janeiro: Editora FGV. 2009.

FREIRE, Maria Martha de Luna.

Ser mãe é uma ciência: mulheres, médicos e a construção da maternidade científica na década de 1920. História, Ciências, SaúdeManguinhos, Rio de Janeiro, v.15, supl.1, p.153-171. 2008.

FREIRE, Maria Martha de Luna; FERREIRA, Luis Otávio.

Medicina, filantropia, assistência à infância e a fundação do Hospital de Crianças da Bahia, 1920-1930. In: Barreto, Maria Renilda Nery; Souza, Christiane Maria Cruz de (Ed.). História da saúde na Bahia: instituições e patrimônio arquitetônico (1808-1958). Rio de Janeiro: Editora Fiocruz; São Paulo: Manole. 2011.

MARTINS, Ana Paula Vosne.

História da maternidade no Brasil: arquivos, fontes e possibilidades de análise. Trabalho apresentado no 23. Simpósio Nacional de História, 17-22 jul. 2005. Londrina. 2005.

MOTT, Maria Lúcia B.

Gênero, medicina e filantropia: Maria Rennotte e as mulheres na construção da nação.

Cadernos Pagu, Campinas, v.24, p.41-67. 2005.
MOTT, Maria Lúcia B.

Maternalismo, políticas públicas e benemerência no Brasil (1930-1945). Cadernos Pagu, Campinas, v.16, p.199-234. 2001.

NARI, Marcela.

Las políticas de maternidad y maternalismo político. Buenos Aires, 1890-1940. Buenos Aires: Biblos. 2004.

OLINTO, Plínio.

Boletim da Pro Matre, Rio de Janeiro, ano 4. abr. 1940.

\section{REGISTRO...}

Registro do Instituto de Proteção e Assistência à Infância da Bahia. Cartório do 1o Ofício do Registro Especial de Títulos e Documentos e do Registro Civil das Pessoas Jurídicas, livro A, n.1, p. 52-53. 20 mar. 1911

SANGLARD, Gisele Porto.

Entre os salões e o laboratório: Guilherme Guinle, a saúde e a ciência no Rio de Janeiro, 19201940. Rio de Janeiro: Editora Fiocruz, 2008.

ZÁRATE, María Soledad.

Dar a luz en Chile, siglo XIX: de la 'ciencia de hembra' a la ciencia obstétrica. Santiago: Dirección de Bibliotecas, Archivos y Museos; Universidad Alberto Hurtado, 2007. 